\title{
What Happened to Our Environment and Mental Health as a Result of Hurricane Sandy?
}

\author{
Shao Lin, MD, PhD; Yi Lu, MD; John Justino, MBA; Guanghui Dong, MD, PhD;
} Ursula Lauper, MA, MPH

\section{ABSTRACT}

Objectives: This study describes findings of the impacts of Hurricane Sandy on environmental factors including power outages, air quality, water quality, and weather factors and how these affected mental health during the hurricane.

Methods: An ecological study was conducted at the county level to describe changes in environmental factors - especially power outages - and their relationships to emergency department (ED) visits for mental health problems by use of a Poisson regression model.

Results: We found that many environmental hazards occurred as co-exposures during Hurricane Sandy in addition to flooding. Mental health ED visits corresponded with the peak of maximum daily power blackouts, with a 3-day lag, and were positively associated with power blackouts in Bronx (prevalence ratio [PR]: 8.82, 95\% confidence interval [CI]: 1.27-61.42) and Queens (PR: 2.47, 95\% Cl: 1.05-5.82) counties. A possible dose-response relationship was found between the quantile of maximum blackout percentage and the risk of mental health in the Bronx.

Conclusion: We found that multiple co-environmental hazards occurred during Hurricane Sandy, especially power blackouts that mediated this disaster's impacts. The effects of power outage on mental health had large geographic variations and were substantial, especially in communities with low sociodemographic status. These findings may provide new insights for future disaster response and preparedness efforts. (Disaster Med Public Health Preparedness. 2016;10:314-319)

Key Words: Hurricane Sandy, environment, power outage, mental health

$\mathrm{H}$ urricane Sandy was the largest storm ever recorded in the Atlantic Ocean, resulting in 117 deaths and approximately $\$ 50$ to $\$ 65$ billion in damages. ${ }^{1}$ It struck the northeastern United States the evening of Monday, October 29, 2012. The Sandy-affected areas in New York state suffered widespread resource loss, prolonged power outages (blackouts), and disruption to transit systems, health care services, and social systems. Although several anecdotal reports or case studies reported environmental impacts after Hurricane Sandy, ${ }^{2-4}$ few studies have systematically described the environmental impacts, especially multiple environmental factors and their relationship to mental health. This article describes preliminary findings of the impacts of Hurricane Sandy on multiple environmental factors (blackouts, air and water quality, and weather factors), and how these factors affected mental health in New York state.

\section{METHODS}

\section{Study Population and Exposure Definition}

The study population consisted of all persons regardless of age who resided in the 8 counties in southern
New York state, which included 5 New York City (NYC) counties (Bronx, Queens, Kings, Richmond, and New York) and 3 upstate counties (Nassau, Suffolk, and Westchester). A modified definition of the Hurricane Sandy period was defined as October 28, 2012, to November 9, 2012, by the Federal Emergency Management Agency (FEMA) to better focus on Sandy's impact in New York state.

\section{Data Sources and Variable Definition Emergency Department Visit Data}

Information on daily emergency department (ED) visits was obtained from the New York State Department of Health (NYSDOH) Statewide Planning and Research Cooperative System (SPARCS). SPARCS is a legislatively mandated database with complete coverage for approximately $95 \%$ of New York state hospitals (excluding federal and psychiatric facilities). SPARCS data include patient information on principal and other diagnoses, date of birth, gender, race, ethnicity, street address, and admission date. The data reported by hospitals are reviewed by the SPARCS administrative staff for accuracy and completeness. For this study, we identified and 
geocoded mental health ED visits (International Classification of Diseases [ICD] codes: 290-299, 300-316, 980, E950959) during Hurricane Sandy from SPARCS. Access to these data was granted by the NYSDOH Institutional Review Board and the SPARCS Data Protection Review Board.

\section{Power Outage Data}

Blackout data were obtained from the Electric Outage Reporting System recorded by the New York State Department of Public Service. This system focuses on keeping records during major blackout events. During Hurricane Sandy, the number of blackouts was reported twice per hour.

\section{Meteorological Data}

Meteorological data including daily or hourly temperature, dew points, barometric pressure, snowfall, snow depth, wind speed, and wind direction were obtained from the National Center for Atmospheric Research and the National Weather Service.

\section{Air Pollution Data}

Ambient air pollutant data including ozone $\left(\mathrm{O}_{3}\right)$ and particulate matter $\left(\mathrm{PM}_{2.5}\right)$ were obtained from the New York State Department of Environmental Conservation (NYSDEC), which measures hourly $\mathrm{O}_{3}$ concentrations every day (ppb) and 24-hour averaged $\mathrm{PM}_{2.5}$ levels. Because the ozone season had passed by the time of the Hurricane Sandy period, this study focused mainly on $\mathrm{PM}_{2.5}$.

\section{Study Design and Statistical Analysis}

This was an ecological study to evaluate environmental and mental health data and their relationship in 8 Sandy-affected counties. The daily maximum number of households with blackouts and the daily maximum percentage of blackouts (calculated by using daily maximum number of blackouts divided by the total customers in each county) were used to represent the impact of power blackouts. The daily prevalence of mental health-related ED visits was calculated by using the daily number of mental health ED visits divided by the population of each county based on the 2010 census. Poisson regression was used to assess the association between blackouts and mental health-related ED visits in the affected area. Adjusted prevalence ratios (PRs) and 95\% confidence interval (CIs) were calculated for the overall study area and individual counties controlling for day of the week effect. We also evaluated a potential dose-response relationship by categorizing the maximum percentage of blackout into quartiles and then comparing the PRs for each quartile with the lowest quartile (as the reference).

\section{RESULTS}

\section{Power Outages and Mental Health}

We examined the daily maximum number of blackouts in each of the affected counties and found that Suffolk County had the highest daily maximum number of blackouts (470,000 households), followed by Nassau County $(450,000)$ and NYC (approximately 290,000). The peak for blackouts in most counties occurred on October 30, 2012. In addition, Nassau County had the highest percentage of households without power $(94.4 \%)$, followed by Suffolk $(77.8 \%)$ and Richmond (69.5\%) counties. In terms of blackout duration, Nassau had the longest recovery period (through November $12,2012)$ and the highest impact $(>50,000$ residences without power). Although Manhattan also experienced wide blackouts $(40.5 \%)$, it recovered within 5 days.

Our preliminary findings (Figure 1A) showed that the overall daily mental health prevalence was 4.95 per 100,000 . The counties with the highest prevalence of mental health diseases during the Sandy period were Bronx (7.15), Kings (6.44), and New York (6.38), respectively. Among all subtypes of mental health problems, substance abuse had the highest overall prevalence $(2.54 / 100,000)$. The counties of New York, Bronx, and Kings had the highest substance abuse rates $(3.99,3.52$, and 3.30 per 100,000 , respectively). For other mental health problems, such as psychosis, mood disorder, and suicide, Bronx County had the highest rates. The 5 NYC counties experienced higher rates of total and various mental health problems than the upstate New York counties. In addition, mental health ED visits corresponded with the peak of maximum daily percentage of blackouts, with a case peak on November 3, three days after the blackout peak, as described in Figure 1B.

Although a marginally overall protective effect was found after the blackouts (Figure 1C), mental health ED visits were positively associated with blackouts in Bronx (PR: 8.82, 95\% CI: 1.27-61.42) and Queens (PR: 2.47, 95\% CI: 1.05-5.82) counties. When the distribution of maximum blackout was divided into quartiles (data not shown), we observed a possible dose-response relationship (ie, the higher the quantile of maximum percentage of blackout, the higher the risk of mental health ED visits) in the Bronx.

\section{Air Quality, Water Quality, and Weather Effects on Mental Health}

As described in Figure 2, fine particulate levels of $\mathrm{PM}_{2.5}$ in the 8 affected counties during the Sandy period appeared to be lower than almost all the levels in the previous years, although the confidence intervals covered each other. We also found that there were no significant changes in the levels of physiochemical properties and microbacterial contamination in drinking water in the 8 affected counties during the Sandy period compared to the water data in prior years. Fire broke out in Queens County as a result of this superstorm on October 29, 2012, followed by a peak of ED visits (113 cases) due to mental health problems on the next day. We observed increased numbers of mental health cases (but not statistically significant) in the days with fire during the Hurricane Sandy 
Power Outages During Hurricane Sandy and Mental Health-Related ED Visits.

(A)

\begin{tabular}{cccccccc}
\hline County & \multicolumn{6}{c}{ Average daily Emergency Department (ED) visit rate $(\mathbf{1 0 0 , 0 0 0 )}$} \\
\hline & All types & Anxiety & $\begin{array}{c}\text { Adjustment } \\
\text { Disorder }\end{array}$ & Psychosis & $\begin{array}{c}\text { Mood } \\
\text { disorder }\end{array}$ & $\begin{array}{c}\text { Substance } \\
\text { Abuse }\end{array}$ & Suicide \\
\hline All counties & 4.95 & 0.51 & 0.58 & 0.57 & 0.70 & 2.54 & 0.07 \\
\hline Bronx & 7.15 & 0.55 & 0.67 & 1.08 & 1.19 & 3.52 & 0.14 \\
\hline Kings & 6.44 & 0.57 & 0.97 & 0.73 & 0.82 & 3.30 & 0.05 \\
\hline Nassau & 2.45 & 0.52 & 0.28 & 0.22 & 0.38 & 1.01 & 0.04 \\
\hline New York & 6.38 & 0.38 & 0.90 & 0.27 & 0.80 & 3.99 & 0.05 \\
\hline Queens & 4.16 & 0.44 & 0.41 & 0.47 & 0.63 & 2.13 & 0.09 \\
\hline Richmond & 4.05 & 0.53 & 0.46 & 0.27 & 0.48 & 2.28 & 0.04 \\
\hline Suffolk & 3.13 & 0.57 & 0.27 & 0.23 & 0.44 & 1.56 & 0.06 \\
\hline Westchester & 3.24 & 0.53 & 0.20 & 0.39 & 0.61 & 1.44 & 0.07 \\
\hline
\end{tabular}

(B)

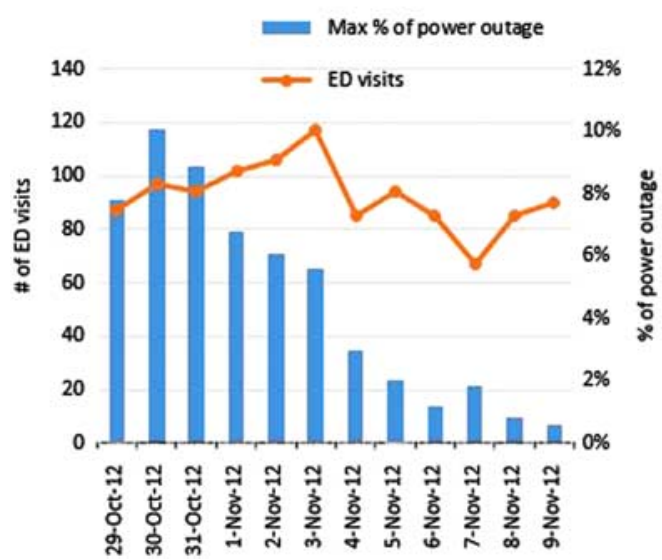

(C)

\begin{tabular}{lccc}
\hline Patient county & PRs & $95 \%$ Cls & P \\
\hline Overall & 0.995 & $0.83,1.20$ & 0.96 \\
\hline Bronx & $\underline{\mathbf{8 . 8 2}}$ & $1.27,61.42$ & $\underline{\mathbf{0 . 0 3}}$ \\
\hline Kings & 2.14 & $0.33,13.71$ & 0.42 \\
\hline Nassau & 0.88 & $0.47,1.65$ & 0.70 \\
\hline New York & 0.81 & $0.57,1.16$ & 0.25 \\
\hline Queens & $\underline{2.47}$ & $1.05,5.82$ & $\underline{0.04}$ \\
\hline Richmond & 0.87 & $0.46,1.64$ & 0.66 \\
\hline Suffolk & 0.91 & $0.62,1.35$ & 0.64 \\
\hline Westchester & 0.88 & $0.47,1.65$ & 0.70 \\
\hline -Adjusted for Day of the Week, Patient County. &
\end{tabular}

(A) ED visit rate (cases per 100,000) during the 12-day Hurricane Sandy period (0ct 29 - Nov 9) by county and subtype. (B) Trends in mental healthrelated ED visits and percentage of power outage during the 12-day Hurricane Sandy period (Oct 29 - Nov 9) in Bronx County. (C) Adjusted PRs of the association between the maximum percentage of power outage and ED visits in 8 affected counties during the 12-day Hurricane Sandy period. Abbreviations: $\mathrm{Cl}$, confidence interval; ED: emergency department; PR, prevalence ratio.

period. On November 7, 2012, a winter storm hit New York state, creating an early snowfall with lower air pressure, higher wind speed, lower visibility, and higher precipitation than usual. On the day after the snowstorm, most counties saw a further increase in blackouts. The mental health cases seen on the snow day were lower, with an increase in cases after 1 to 2 lag days following the snowfall.

\section{DISCUSSION}

\section{Environmental Changes During Sandy}

Loss of power after Hurricane Sandy probably posed the greatest and most direct public health threat, with the largest direct impact being on households in the 5 NYC counties owing to their large population. Nassau County experienced the largest impact from blackout, demonstrated by the highest percentage outage and longest power recovery period. New York County had the fastest power recovery among the affected counties, which may demonstrate the local government's rapid and effective responses. Interestingly, although Queens and Kings counties are located next to Nassau County, they suffered much less blackout, which may also indicate the effectiveness of disaster response efforts by NYC governments. The potential impacts from this superstorm may have been reduced by joint and timely efforts from multiple state and federal agencies, including providing more than 170 medical shelters for providing care, establishing 68 Disaster Recovery Centers, and supplying more than 1 million liters of water and 1 million meals to those in need within 24 hours. ${ }^{5}$

The current study found lower levels of $\mathrm{PM}_{2.5}$ measured by routine monitors in all 8 affected counties during the Sandy period, compared to prior years, which is consistent with NYSDEC $^{6}$ and US Environmental Protection Agency (EPA) reports. ${ }^{7}$ This could have been due to higher precipitation, 
FIGURE 2

Concentration of Fine Particulate Matter $\left(\mathrm{PM}_{2.5}\right)$ in the 8 Affected Counties During the Hurricane Sandy Period.

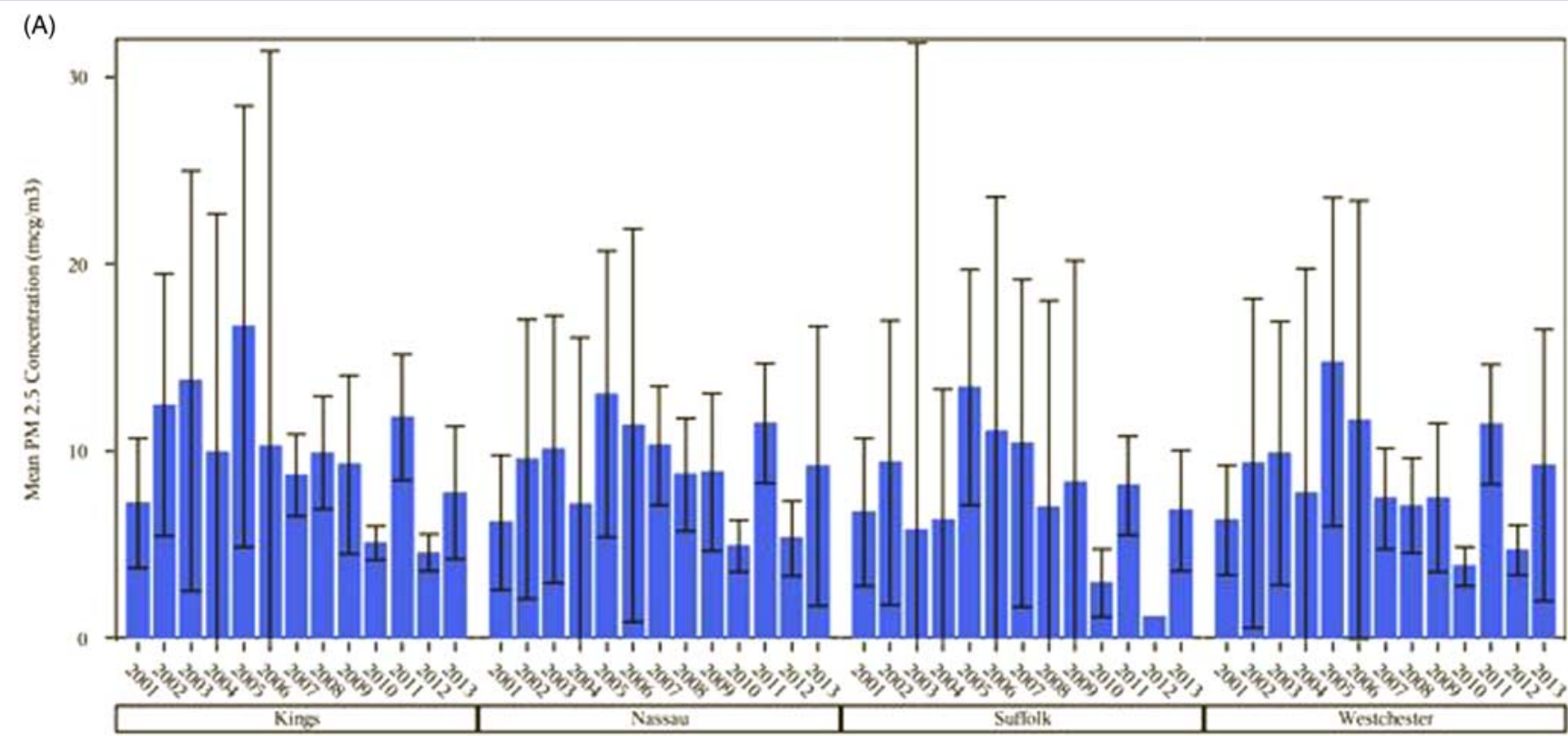

(B)

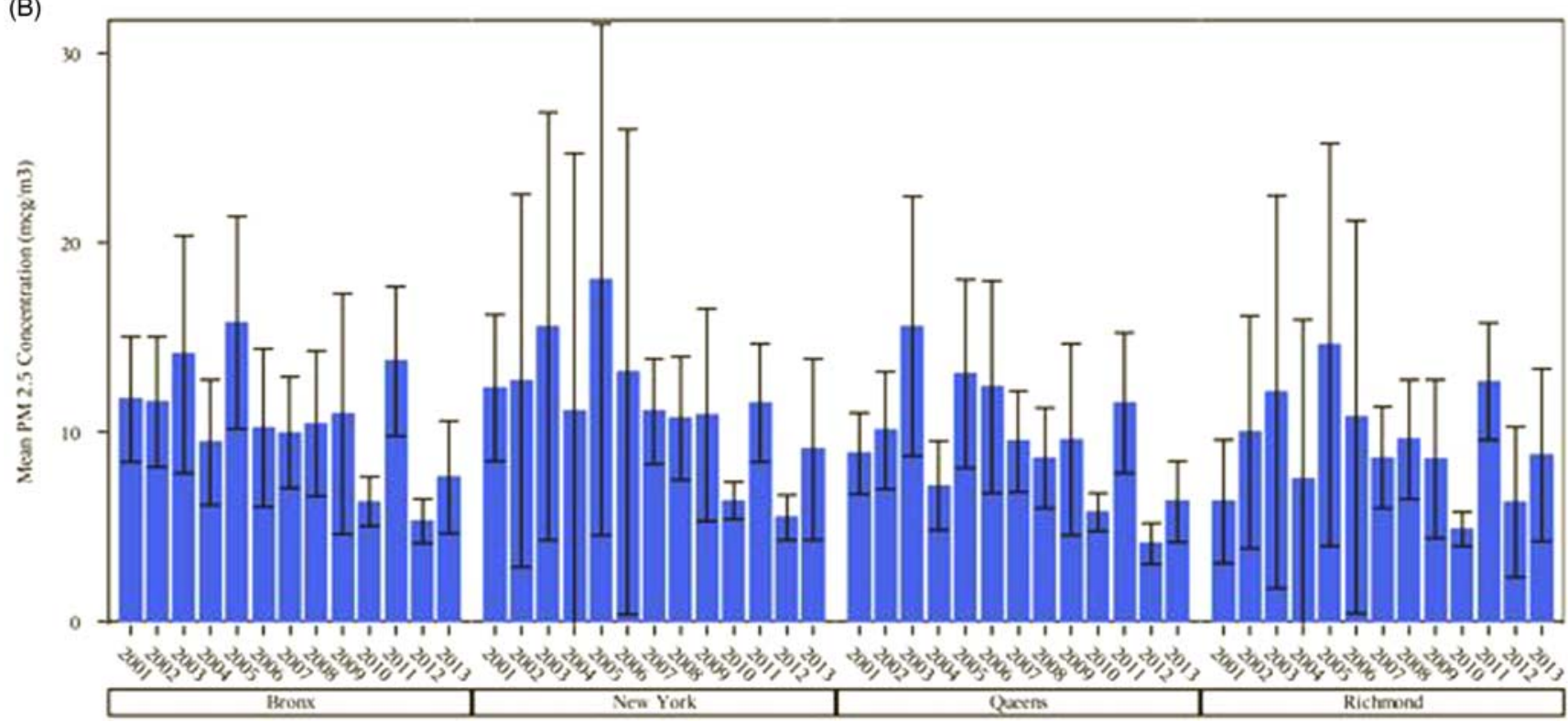

less traffic, and many power plants or industrial facilities shutting down as a result of the blackouts. However, additional monitors set up by NYSDEC ${ }^{6}$ in lower Manhattan recorded $\mathrm{PM}_{2.5}$ levels exceeding the EPA's 24-hour standard for 2 days (November 15-16, 2012). This could have been due to the emissions from widely used temporary generators and building support equipment. ${ }^{6,8}$

Water contamination was a major health concern after Hurricane Sandy. Our data did not demonstrate any obvious evidence of drinking water contamination after Sandy in the affected areas. However, this superstorm knocked out power and damaged approximately 80 sewage treatment systems in New Jersey, which implies that approximately 2.75 billion gallons of untreated waste flowed from the plant into the nearby bay. ${ }^{8}$ Fire posed another hazard to the affected communities as a result of Superstorm Sandy, which could have led to blackouts and affected air quality and therefore may have had impacts on human health. 
An early winter storm and snowfall on November 7, 2012, put the affected residents in an even worse environment, especially for those who lost power and had no heat. The snow and storm may have limited local residents' access to health care facilities during the storm day and may have therefore led to an increase in the number of $\mathrm{ED}$ visits 1 to 2 days after the storm, as access to medical care facilities improved.

\section{Environmental Factors and Mental Health}

Our study found that power outage is one of the most important environmental factors affecting mental health. With every $1 \%$ increase in blackout, Bronx had almost an 8-fold increased risk of mental health ED visits demonstrating a dose-response relationship, and Queens had a 1.5-fold increased risk. We found that mental health ED visits increased after 2 to 3 days of lag following a blackout. Fire and a winter storm and snow were also found to be associated with the increase in mental health problems. However, no relevant literature could be found to compare with our findings. We also found that substance abuse was highest among all subtypes of mental health problems after disasters, which was consistent with the findings in previous literature. 9,10

\section{Geographic Variations and Vulnerabilities}

A large geographic difference in mental illness after Sandy was also found. In addition to the difference in scale or degree of impacts by Sandy in different counties, the regional difference may reflect vulnerability due to health care access and demographics such as hospital density, population density, and sociodemographic composition. Although Nassau County was affected the most by blackouts, we found that Bronx County had the highest rates of overall and multiple subtypes of mental health $\mathrm{ED}$ visits, where there are the highest proportions of Hispanic, African American, and low-income households, as well as low educational levels.

\section{Joint Effects of Environmental Hazards}

As described above, many environmental hazards occurred as co-exposures during Hurricane Sandy, which integrated with each other or interacted with flooding, resulting in potentially negative impacts on health. For instance, flooding (plus the snowstorm) first caused blackout, fire, and water contamination in some areas, and blackouts further worsened air quality (due to the use of generators) and water quality (shutdown of sewage treatment systems). Loss of power may also have led to a joint effect with building environments. This was particularly true for elderly residents living in NYC's high-rise apartments, many of whom were unable to descend stairways and became trapped for days or even weeks as a result of nonfunctioning elevators during periods of prolonged blackout.

\section{CONCLUSION}

We found that multiple co-environmental hazards occurred during Hurricane Sandy, which may have intensified or multiplied this disaster's impacts. Among all environmental hazards, the impact of power outages on mental health seems substantial and had large geographic variations, especially in communities with low sociodemographic status. These findings may provide new insight for future disaster response and public health preparedness efforts.

\section{About the Authors}

Department of Environmental Health Sciences (Dr Lin, Dr Lu, Ms Lauper) and Global Health Program (Dr Lin and Mr Justino), SUNY at Albany School of Public Health, Rensselaer, New York, and Sun Yat-Sen University, School of Public Health, Guangzhou, China (Dr Dong).

Correspondence and reprint requests to Shao Lin, SUNY at Albany School of Public Health, Department of Environmental Health Sciences and Global Health Program, Rensselaer, New York (e-mail: slin@albany.edu).

\section{Acknowledgments}

The authors thank Mr Cris Pantea and Dr Seema Nayak from the Center for Environmental Health (CEH), NYSDOH, and Dr Srishti Shrestha from NIEHS for their support on data management, analysis, and result table preparation. We also thank the staff and administrators from The Bureau of Environmental and Occupational Epidemiology, $\mathrm{CEH}$, for their support on this project.

\section{Funding}

FOA title: CDC RFA-TP13-001, Centers for Disease Control and Prevention, Public Health

Preparedness and Response Research to Aid Recovery from Hurricane Sandy. Grant project title: Assessing Multiple Health Endpoints, Vulnerability and Risk factors in the Aftermath of Hurricane Sandy in New York State. NOA: 1U01 TP000566-01.

Published online: April 18, 2016.

\section{REFERENCES}

1. Blake ES, Kimberlain TB, Berg RJ, et al. Tropical cyclone report Hurricane Sandy (AL182012) 22-29 October 2012. http://www.nhc. noaa.gov/data/tcr/AL182012_Sandy.pdf. Published February 12, 2013. Accessed March 25, 2016.

2. Mooney J. By the numbers: hurricane Sandy's environmental impact. NJ Spotlight website. www.njspotlight.com/newsletters/. Published December 4, 2012. Accessed November 20, 2015.

3. Coyle K. Hurricane Sandy's impact on fish and wildlife. National Wildlife Federation website. http://blog.nwf.org/2012/10/hurricanesandys-impact-on-fish-and-wildlife/. Published October 30, 2012. Accessed November 20, 2015.

4. Blaszczak J. The environmental impacts of Hurricane Sandy. Wegowise website. http://blog.wegowise.com/2012-11-06-the-environmentalimpacts-of-hurricane-sandy. Published November 6, 2012. Accessed November 20, 2015.

5. Dirk F. The air quality impact of Super Storm Sandy and the mitigation strategies that could have helped. 2013 EMEP Conference. http://www. nyserda.ny.gov/-/media/Files/Events/Events-and-Conferences/EMEP-2013/ presentations/2013-felton.pdf. Accessed November 25, 2015.

6. EPA. Hurricane Sandy response and recovery: Air Monitoring Results. EPA website. http://archive.epa.gov/region02/sandy/web/html/. Updated November 18, 2015. Accessed November 20, 2015. 2012. 
7. Manuel J. The long road to recovery: environmental health impact of hurricane Sandy. Environ Health Perspect. 2013;121(5): A152-A159.

8. Byme M. New York. One month after Sandy (weblog entry). Washington, DC: Federal Emergency Management Agency, US Department of Homeland Security; 2013. http://goo.gl/55IZU. Accessed April 15, 2013.
9. Williams AR, Tofighi B, Rotrosen J, et al. Psychiatric comorbidity, red flag behaviors, and associated outcomes among office-based buprenorphine patients following Hurricane Sandy. J Urban Health. 2014;91(2):366-375.

10. Cepeda A, Valdez A, Kaplan C, et al. Patterns of substance use among Hurricane Katrina evacuees in Houston, Texas. Disasters. 2010; $34(2): 426-446$. 